Article

\title{
Studies on Charges for Sea Area Utilization Management and Its Effect on the Sustainable Development of Marine Economy in Guangdong Province, China
}

\author{
Lijing Yang ${ }^{1,+* *}$, Ping Wang ${ }^{1,+}$, Linglong Cao ${ }^{1, *}$, Yongjian Liu ${ }^{2}$ and Lei Chen ${ }^{1}$ \\ 1 South China Sea Institute of Planning and Environmental Research, State Oceanic Administration People's \\ Republic of China, Guangzhou 510300, China; wangping@scsb.gov.cn (P.W.); chenlei@scsb.gov.cn (L.C.) \\ 2 Guangdong Jiayuan Metals Co., Ltd., People's Republic of China, Guangzhou 510300, China; \\ allen@jycmetal.com (Y.L.) \\ * Correspondence: yanglijing@scsb.gov.cn (L.Y.); cll@scsb.gov.cn (L.C); Tel.: +86-20-8429-3791 (L.Y.); \\ +86-20-8421-2787 (L.C.); Fax: +86-20-8421-2919 (L.C.) \\ + These authors contributed equally to this work.
}

Academic Editor: Marc A. Rosen

Received: 23 October 2015; Accepted: 20 January 2016; Published: 27 January 2016

\begin{abstract}
Marine economy plays an important role in the growth of the global economy. With its continuous development in the past years, the driving roll of marine economy in China's economy has become remarkable. It is of strategic significance for China's economic sustainable development to strengthen the exploration of marine resources and promote the quality and profit of the marine economy. To explore sustainable marine resources, one important economic management method is to implement paid use system, specify marine resource property rights and collect Charges for Sea Area Utilization (CSAU). With the approval of the "Guangdong Marine Economic Experimental Zone Program", Guangdong province targets the building of an economically strong marine province. The collection and rational expenditure of CSAU not only play a positive role in the rapid and sustainable development of the marine economy, but also offer financial guarantee and support for the building of an economically strong marine province. In this paper, the CSAU collection and expenditure in the past decade after the issuance of the Sea Area Use Management Law and the corresponding performance were evaluated and analyzed, and the problems in the CSAU collection and management were discussed. Furthermore, countermeasures were proposed to perfect the CSAU expenditure management policy, define the distribution proportion at all levels, optimize the expenditure structure, and strengthen the supervision and management mechanism. The results and conclusion of this paper could not only greatly promote the construction of marine economy, rational development and sustainable use of marine resources, but also provide a reference for other coastal provinces in China.
\end{abstract}

Keywords: charges for sea area utilization; collection; expenditure; sustainable development; marine economy; Guangdong

\section{Introduction}

With the continuous acceleration of industrialization and urbanization in China, more and more attention has been focused on the coastal areas, and a new wave of immigration for marine exploration has been initiated. It has become more and more challenging since 2000 to manage the sea area effectively with the increasing demands of sea use, the prominence of sea use conflicts and the aggravation of the shortage of sea area resources. There is an urgent need to improve 
the comprehensive management capability in marine exploration, protection and control in order to adapt to the new situation of marine management and promote the sustainable management of the marine economy [1-3]. In 1992, the Rio Declaration defined sustainability theory. Sea area use sustainability should incorporate the sustainability of the marine economy, marine ecological resources and society. The present offshore exploration in China is developing very fast, especially the construction of port wharfs, power plants and land reclamation, which brings a rapid growth of marine economy, as well as the high pressure of heavy pollution, degraded environment quality, and depleted biological resources and frequent marine disasters that are harmful for the sustainable development of the marine economy. As the province with the highest Gross Ocean Product (GOP) in China, Guangdong province is located in the Pearl River Delta, with superior geographical position, rich marine resources and the longest coastline, it is very active in the marine activities, which require a higher standard in the CSAU management $[4,5]$. With the approval of the "Guangdong Marine Economic Experimental Zone Program", Guangdong province has been focusing on accelerating economic transformation and upgrade, using the marine economy comprehensive experimental zone as a platform to optimize the spatial layout of marine exploration, strengthening marine comprehensive management including CSAU management, and exploring the economically strong marine province. In this context, Guangdong should grasp this chance, on the basis of the current marine development progress, with the assistance of related policy, finance and management, to maximize the leverage function of CSAU and coordinate its collection and expenditure in order to promote the scientific and healthy development of the marine economy. Collection and rational expenditure of CSAU would provide more financial guarantee and support for the 12th Five-Year Plan on the development of marine economy and construction of a comprehensive experimental zone. It is also an important impetus for Guangdong province to be the first marine economically strong province. However, Guangdong has also faced many tough problems, especially the pollution resulting from offshore exploration and the depletion of marine resources (Statement of the Marine Environment in Guangdong Province). The government allocates a large sea area for various marine projects, from which the CSAU collected is rarely used in the marine environment protection and disaster prevention, having little effect on the promotion of marine economy's sustainable development. However, the current studies on CSAU management mainly focus on CSAU's collection status, which is usually more or less incomplete and superficial due to the limitation of data sources. In other words, we still lack in-depth studies of CSAU's expenditure management and its influence on the sustainable development of marine economy. Due to the limitation of data sources, current studies on CSAU collection and expenditure in Guangdong Province are superficial, and studies on CSAU management as well as its effect on the sustainable development of marine economy are relatively lacking. Therefore, the purpose of this paper was: to offer pioneering studies on the promotion of CASU in the rational exploration and use of sea area resources, to propose the countermeasure for the sustainable development of marine economy, and to provide support for the improvement of the management of economic instruments in China [5-7]. As a financial instrument of marine governance, CSAU could be also a reference for other countries in exploring sea area and sustainably developing the marine economy.

\section{CSAU Collection in Guangdong Province}

\subsection{Current Situation of Sea Area Paid-Use Management in Guangdong Province}

The sea area paid-use management system in China dates from 1993, when the "Provisional Regulation of State Sea Area Use Management", jointly issued by the Ministry of Finance and the State Oceanic Administration, was promulgated and implemented. The said Regulation specified the sea area paid-use system, regulated the sea area paid-use details, divided the sea area use charges into three types (sea area approval taxes, sea area transfer taxes and sea area rents), and stipulated the collection standard of sea area approval taxes. The purpose of the Regulation was to solve the phenomena of "out of order, out of control and free of charge" in sea area use and ensure the sustainable 
development and exploration of the sea area. Despite the positive influence on solving the severe problems of the sea area use in China, this Regulation still lacks a unified standard and is difficult to implement due to its low legal level and insufficient authority. Therefore, it was not surprising that the Regulation could not completely solve the problem of plundering sea area resources [7]. In 2002, the Sea Area Use Management Law was implemented, which established the property rights systems of marine resources and sea area paid-use, respectively by stipulating that the sea area belongs to the state and that the ownership of sea area can be exercised in the form of CSAU collection. It remarkably enhanced the sea area management, avoided the unorganized and wasteful exploration of sea area resources, and promoted the rational allocation of state-owned sea area resources [7]. The purpose of CSAU collection was to put the sea area paid-use system into effect, and it was also the only financial instrument in China' sea area use management (China's sea area management instruments include legal, administrative and financial instruments. The legal instrument contains the Sea Area Use Management Law and the matching regulations; the administrative instrument means the hierarchical governance system; the financial instrument is the CSAU. Generally, the sea area management is proceeded by the provincial government, but those sea area use projects of great significance should be reported to central government. The provincial government collects CSAU, $30 \%$ of which should be turned into central finance, 70\% kept in provincial finance). Through CSAU collection, the sea area users were offered a certain authorized sea area, which could avoid the arbitrariness and waste of sea area exploration and to some extent ensure the sustainability of sea area use. Since then the CSAU collection has been increased sharply, the oceanic administration has been strengthened significantly, and the financial revenue has been increased accordingly. Consequently, the CSAU was collected in the 11 coastal provinces (Figure 1), and as China's Marine Economic Comprehensive Development Experimental Zone, Guangdong province has been always leading in sea area use and management. In 2005, "Provisional Regulation of CSAU Collection in Guangdong Province" was officially released, which for the first time defined the CSAU's distribution proportion and principle. As stated by the Regulation, the CSAU collected from aquaculture use should be turned over to the local Treasury. It also standardized the range and procedure of CSAU discount, defined that CSAU should be mainly used in sea area's renovation, exploration, protection and management based on the principles of "overall arrangement and earmarking", and should provide sustainable funds for the management of a sea area [6].

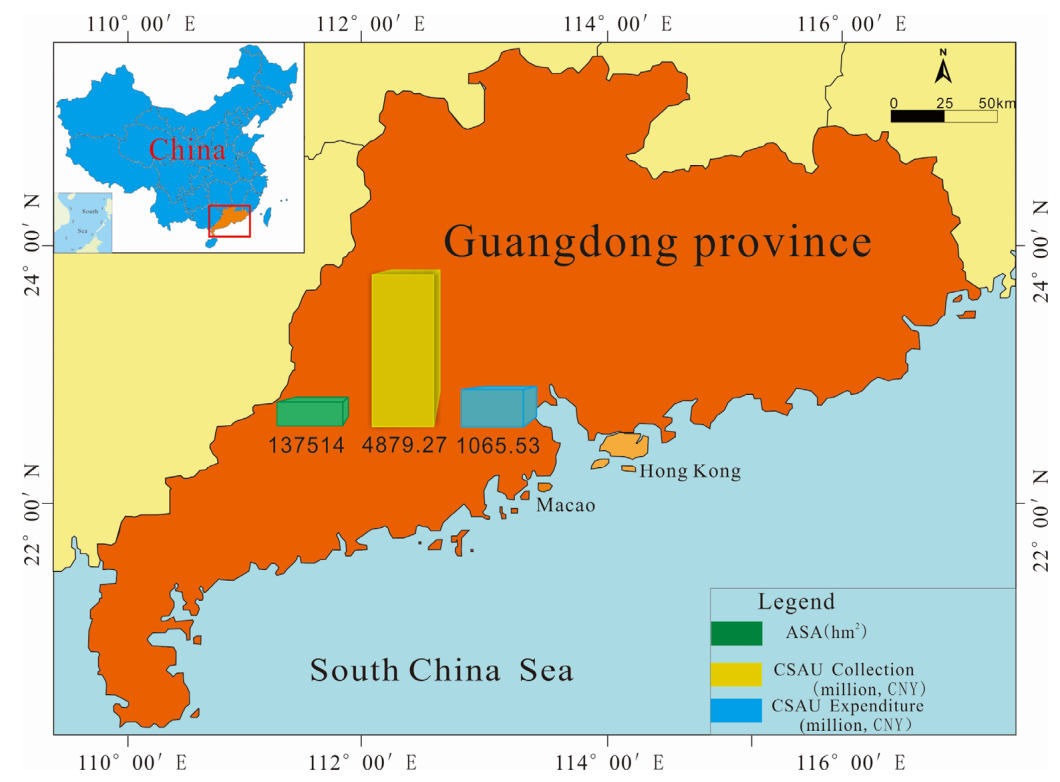

Figure 1. Authorized sea area (ASA) and Charges for Sea Area Utilization (CSAU) collection and expenditure during 2002-2012 in Guangdong province. 


\subsection{CSAU's Collection in Guangdong Province}

The CSAU collection in Guangdong province has acquired legal support and has been gradually incorporated into the standardized, scientific and institutionalized track since the implementation of Sea Area Use Management Law. With the increase of marine activities and the normalization of marine behavior, the acreage of Authorized Sea Area expanded continuously (Table 1), and the Gross Ocean Product (GOP) also increased every year. As shown in Figure 2, the fluctuation of Authorized Sea Area exhibited the same trend as the GOP and the increase in the use of the sea could to some extent promote the growth of GOP. In general, the two indexes showed a tendency of alternative increase before 2007 and the growth rate of GOP was faster than that of Authorized Sea Area during 2007-2012 (Figure 3), indicating that the utilization of sea area has been continuously increasing with better overall benefits. The growth of GOP did not entirely rely on the consumption of marine resources, and the development of marine economy gradually disengaged from dependence on consumption of marine resources, and the marine economic growth pattern gradually shifted from extensive to intensive.

Table 1. Sea area use and economic growth during 2002-2012 in Guangdong province [8-10].

\begin{tabular}{ccccc}
\hline Year & $\begin{array}{c}\text { Growth of Authorized } \\
\text { Sea Area(\%) }\end{array}$ & Growth of GOP(\%) & $\begin{array}{c}\text { Growth of GDP in } \\
\text { Guangdong(\%) }\end{array}$ & $\begin{array}{c}\text { Proportion of CSAU in } \\
\text { Financial Revenue(\%o) }\end{array}$ \\
\hline 2002 & - & - & - & 0.03 \\
2003 & 58.13 & 14.31 & 13.60 & 0.21 \\
2004 & 42.37 & 53.69 & 14.20 & 0.08 \\
2005 & 28.48 & 44.12 & 14.10 & 0.16 \\
2006 & 20.08 & -4.07 & 14.80 & 0.05 \\
2007 & 32.94 & 10.18 & 14.90 & 1.01 \\
2008 & 12.70 & 28.52 & 10.40 & 0.09 \\
2009 & 11.77 & 14.34 & 9.70 & 0.75 \\
2010 & 7.05 & 23.91 & 12.40 & 0.47 \\
2011 & 7.06 & 11.36 & 10.00 & 1.08 \\
2012 & 7.24 & 14.31 & 8.20 & \\
\hline
\end{tabular}

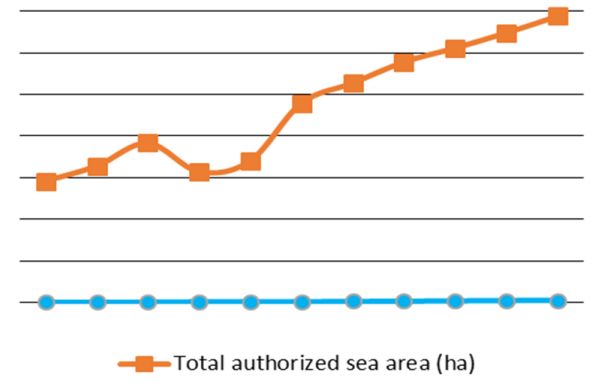

Figure 2. Correlation between authorized sea area and Gross Ocean Product (GOP) in Guangdong province.

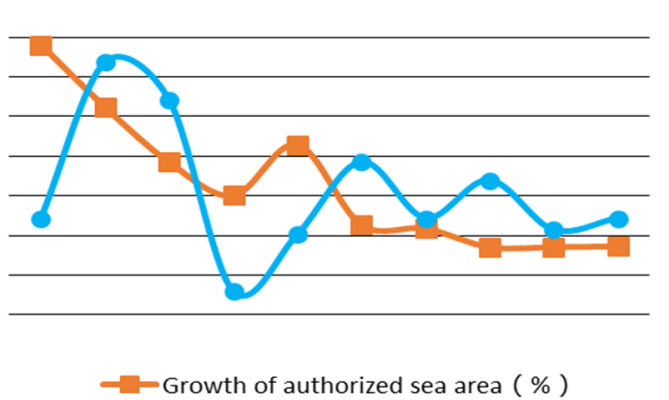

Figure 3. Correlation between growth rates of authorized sea area and GOP in Guangdong province (Statistics before 2002 were not public). 
With the continuous increase of marine activities and acreage of Authorized Sea Area in the past decade, the CSAU collection rose rapidly. In 2002, the CSAU collection was CNY 8.66 million, and increased by 128 times to CNY 1113.48 million in 2012. As shown in Figure 4, the acreage of the Authorized Sea Area followed the same trend as the CSAU collection. Meanwhile, the GOP also tended to increase. In 2002, the GOP was CNY 169.37 billion, and increased 6.2 times to CNY 1050.66 billion in 2012. As shown in Figure 5, there was a positive correlation between CSAU collection and the GOP [11]. Besides, the growth of GOP was faster than that of local GDP, indicating that the increase of marine activities and CSAU collection promoted not only the development of marine economy in Guangdong province, but also the growth of local GDP [12]. Since the issuance of Sea Area Use Management Law, the government collected CSAU and offered certain authorized sea areas to the users. This accelerated the implementation of a sea area paid-use system and sea area property system and made the sea area exploration more organized and rational. With the legal guarantee of the sea area users' rights and interests, the marine activities increased continuously, which also caused an increase of CSAU and the growth of marine economy. CSAU was an instrument of the paid-use system in the legal regulations. With the implementation of sea area paid-use management, the central and local governments promoted the scientific utilization of sea area resources, and the marine economy grew rapidly at a rate even faster than national economy and therefore played an important role in the sustainable development of China's economy $[11,13,14]$.

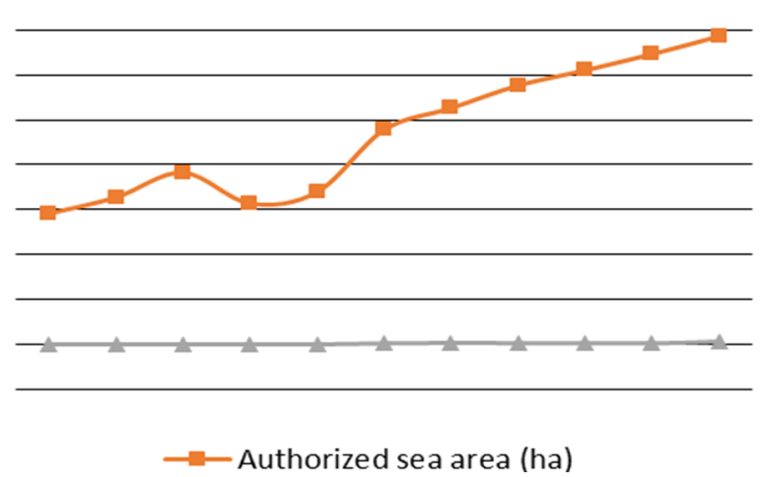

Figure 4. Correlation between authorized sea area and CSAU collection.

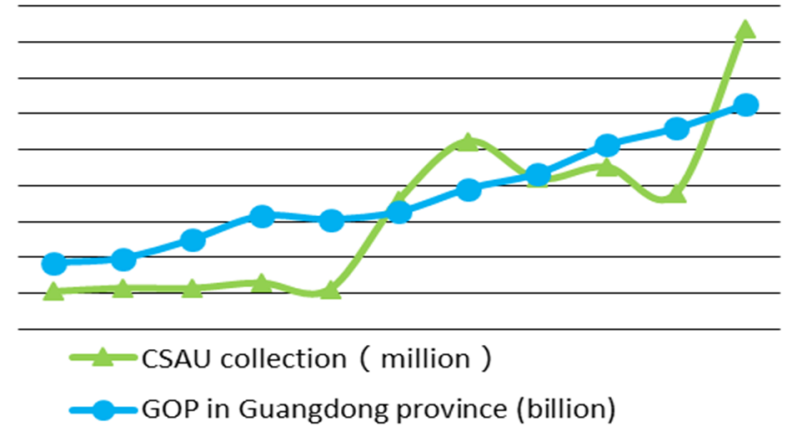

Figure 5. Correlation between CSAU collection and GOP.

During 2002-2012, the financial revenue of Guangdong province increased year by year, the figure in 2002 was CNY 280 billion and increased 4.9 times to CNY1366 billion in 2012. In addition, the proportion of CSAU collection in financial revenue increased by 34.9 times from $0.03 \%$ in 2002 to $1.08 \%$ in 2012. Therefore, it was clear that there was a positive correlation between CSAU collection and financial revenue (Figure 6). The contribution of CSAU collection to financial revenue increased yearly, indicating that the marine activities have been rising. The consequent increase in CSAU 
collection would promote the increase in financial revenue. Similarly, the growth of marine economy could also promote the development of local economy.

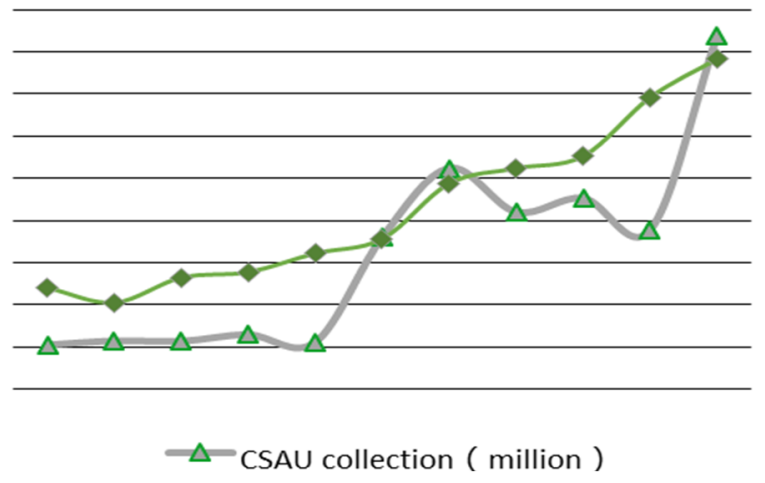

Figure 6. Correlation between CSAU collection and financial revenue in Guangdong province.

With the sea area paid-use system becoming more common in the country, the CSAU collection in Guangdong province has entered a relatively ordered phase. As of 2012, the CSAU collection amounted to CNY 3.4 billion in Guangdong province, one-third of which was turned over to central finance, and two-thirds to the provincial finance. Figure 7 shows the CSAU collection during 2002-2012 in Guangdong province. It can be seen that the CSAU collection rose rapidly, in particular, the annual collection has been more than CNY 100 million since 2007 and was more than CNY 1 billion in 2012. Consequently, the amount turned over to central finance also grew rapidly, and the amount turned over to provincial finance was about 2.3 times of that given to central finance. According to statistics, currently, the CSAU still has a balance of more than CNY 100 million reserved in provincial finance.

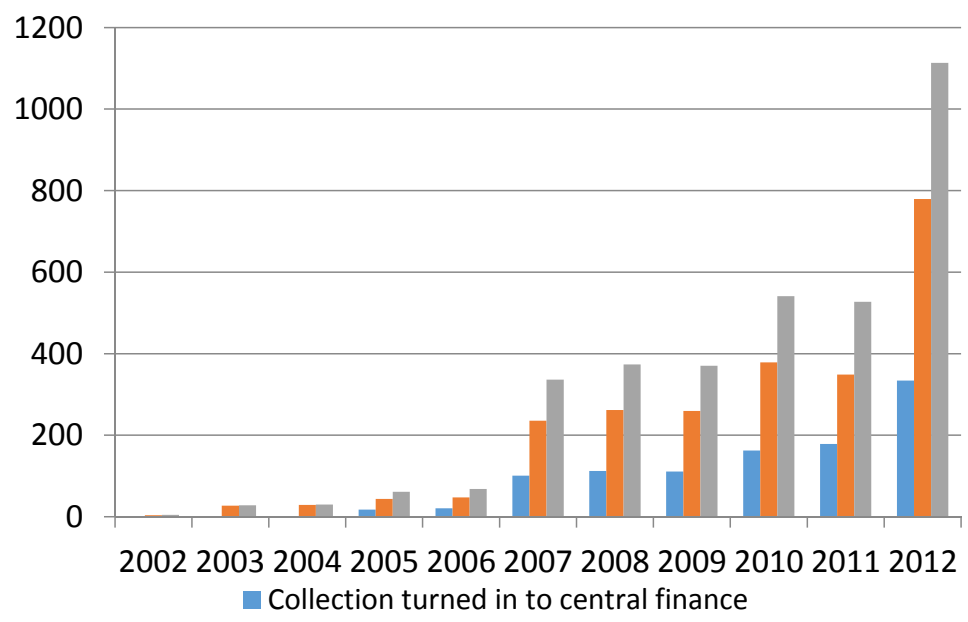

Figure 7. CSAU collection during 2002-2012 in Guangdong Province.

In conclusion, firstly, during 2002-2012 after publication of Sea Area Use Management Law, upon the implementation of sea area resources property system and sea area paid-use system, the efficiency of sea area use increased greatly and the plundering of sea area resources was to some extent restricted, which not only played a constructive role in the marine comprehensive management of Guangdong province and even China, but also promoted the sustainable development of the marine economy as well as the growth of local GDP. Secondly, there was a positive correlation between the Authorized Sea Area and GOP, both of which increased remarkably, indicating that the increased marine activities also promoted the growth of marine economy. Thirdly, the CSAU collection exhibited a synchronous trend with financial revenue, and its proportion in provincial finance increased continuously, demonstrating 
that CSAU collection made a significant contribution to local finance revenue. Fourthly, one-third of the CSAU collection was turned over to the central finance and two-thirds to provincial finance, which was helpful for the local government to be more flexible in the CSAU expenditure. Lastly, the growth of the marine economy gradually got rid of the dependence on the consumption of sea area resources, and instagated a transformation from an extensive pattern to intensive pattern, which would further improve the sustainability of marine economy.

\section{CSAU Expenditure in Guangdong Province}

In 2009, the "Provisional Regulation of CSAU Collection" issued by the State Oceanic Administration was put into effect. It increased the efficiency of sea area utilization and regulated the major CSAU expenditure on the sea area's renovation, protection and governance, which had significant importance in the rational exploration and sustainable utilization of the sea area. As a strong province in marine economy, although Guangdong province's CSAU collection provided renewed impetus to the sustainable development of marine economy, its expenditure performance was not satisfactory [14]. During 2002-2012, the CSAU expenditure in Guangdong province increased continuously (Figure 8), especially in the period of 2008-2012. During 2002-2004, the CSAU expenditure was at its lowest, only CNY 1 million in 2004. However, it rose sharply from 2005. The maximum increase occurred in 2007 and the total amount of CSAU expenditure in 2008 and 2010 was comparable. The expenditure in 2012 reached its peak level. In the expenditure, $72 \%$ was distributed to the city-and-county units, $28 \%$ to the province units.

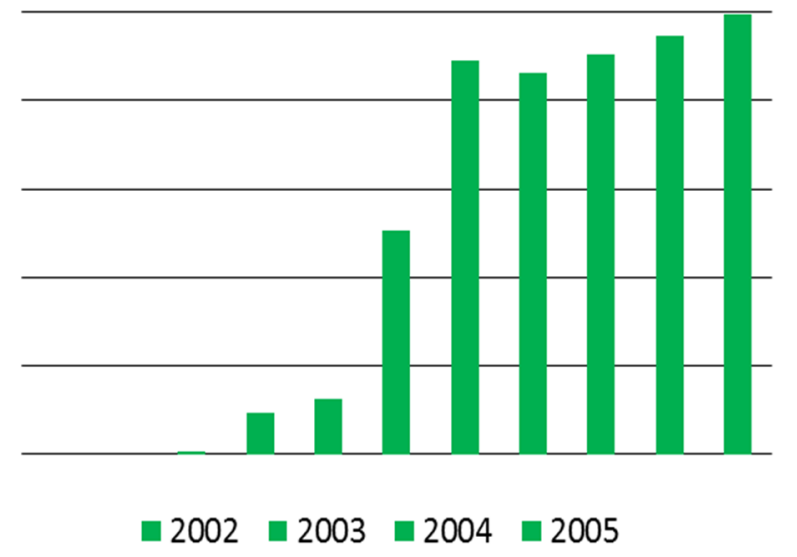

Figure 8. The CSAU expenditure during 2002-2012 in Guangdong Province.

During 2002-2012, of the CSAU collection turned over to central finance, $86 \%$ was refunded for the expenditure, mainly used for marine economy, building of ocean surveillance ships, and renovation and protection of sea area and islands, etc. With regard to the CSAU collection turned over to the provincial finance, two-thirds were distributed to the city-and-county units, and one-third for the provincial expenditure.

The largest proportion of the expenditure from central finance refunds $(60.23 \%)$, was used for renovation and protection of sea area and island, $38.51 \%$ used for building of ocean surveillance ships, and only a small proportion $(1.27 \%$ ) was used for marine economy (The current expenditure of CSAU in marine economy includes studies of marine industry structure and marine economy monitoring system construction) (Figure 9). Of the expenditure from the provincial finance, up to $66.54 \%$ was distributed to the city-and-county units.

During 2010-2012, the average CSAU expenditure was still too little, only accounting for $29.1 \%$ of the collection. The expenditure structures of central finance refunds and the provincial finance were shown in Tables 2 and 3 respectively. 


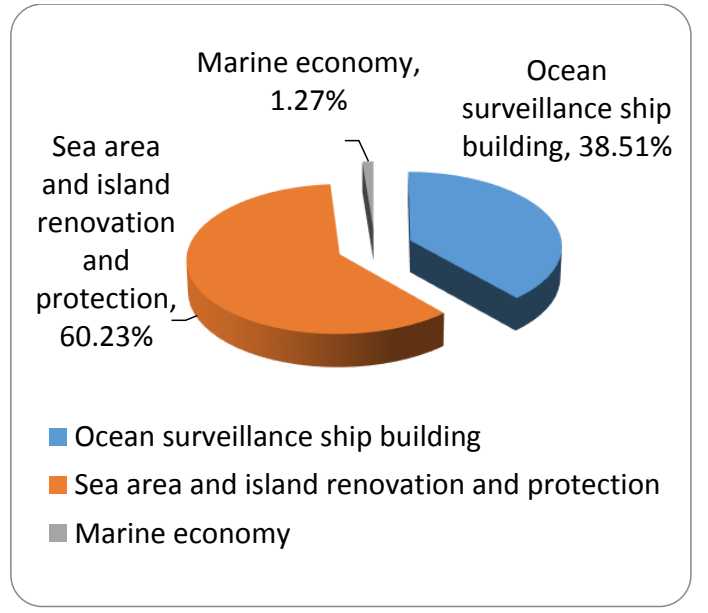

(a)

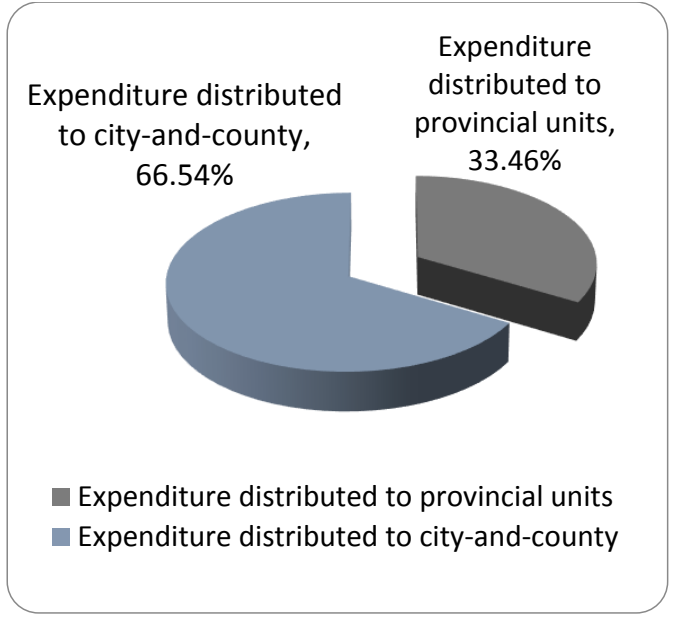

(b)

Figure 9. Expenditure of CSAU from central finance refunding and provincial finance during 2002-2012.

As shown in Table 2, during 2010-2012, the expenditure of CSAU from central finance refunds increased year by year. The proportion used for building of ocean surveillance ships reduced from $83.28 \%$ in 2010 to $16.61 \%$ in 2012 . On the other hand, the proportion used for renovation and protection of sea area and islands increased from $16.72 \%$ in 2010 to $83.39 \%$ in 2012. However, none was used for marine economy in 2010 and 2012, only 3.77\% in 2011 that was used in this category.

Table 2. Expenditure of CSAU from central finance refunding during 2010-2012 (\%).

\begin{tabular}{cccc}
\hline Year & $\begin{array}{c}\text { Building Of Ocean } \\
\text { Surveillance Ships }\end{array}$ & $\begin{array}{c}\text { Sea Area And Island Renovation } \\
\text { And Protection }\end{array}$ & Marine Economy \\
\hline 2010 & 83.28 & 16.72 & 0.00 \\
2011 & 20.31 & 75.92 & 3.77 \\
2012 & 16.61 & 83.39 & 0.00 \\
Average & 38.51 & 60.23 & 1.27 \\
\hline
\end{tabular}

The CSAU expenditure from provincial finance was mainly distributed to province units, city-and-county units and the supporting establishments of fishing port, fishery and ocean surveillance ships. The proportion distributed to city-and-county units was the major part, accounting for $63.45 \%$ (average) during 2010-2012; the proportion distributed to province units was $21.76 \%$ and it was relatively stable; the proportion distributed to the supporting establishments of fishing port and ocean surveillance ships was the lowest but increased continuously from $10.41 \%$ in 2010 to $20.21 \%$ in 2012 (Table 3). Generally, the overall expenditure structure was quite stable.

Table 3. Expenditure of CSAU from provincial finance during 2010-2012 (\%).

\begin{tabular}{cccc}
\hline Year & Province Units & City-And-County Units & Ocean Surveillance Ship \\
\hline 2010 & 21.69 & 67.91 & 10.41 \\
2011 & 22.97 & 64.19 & 12.84 \\
2012 & 20.72 & 59.06 & 20.21 \\
Average & 21.76 & 63.45 & 14.79 \\
\hline
\end{tabular}

Taken together, in the CSAU expenditure from central finance refunds, the government did not pay enough attention to a marine economy that has promising potential, which would affect the development of marine economy and should be fixed soon. A large proportion was distributed to 
the building of ocean surveillance ships, indicating the government's determination to consolidate the oceanic infrastructure construction. The progressive increasing proportion being distributed to the renovation and protection of sea area and island reflected the government's effort to maintain the sustainability of the marine economy. In the CSAU expenditure from provincial finance, the province government supported the development of local marine industries and marine economy, but more proportion should be distributed to city-and-county units with the significant growth of the marine economy in the future.

\section{Effect of CSAU Expenditure}

Figure 10 and Table 4 summarize the changes in the CSAU collection in Guangdong province during 2002-2012. In General, the CSAU collection has been increasing since 2002, reaching the maximum level in 2012 of about 128 fold as compared with that in 2002, indicating that the CSAU collection tended to be standardized and that its contribution to financial revenue increased year by year. Regarding the CSAU expenditure, although it increased by CNY 190 million in 2012 compared to 2002 , the increasing rate was much lower than that of CSAU collection. In contrast, the proportion of CSAU expenditure against collection was decreased instead of increased after 2008 when it reached its peak value of $47.63 \%$. For example, the collection reached its highest level in 2012, but the proportion for expenditure reduced significantly, indicating that the CSAU expenditure was not enough. The investment in sustainable construction of marine industry was even less than the previous years and the investment in infrastructure constructions, marine environmental protection and renovation and the city-and-county units was also reduced, which would be harmful to the sustainable development of marine economy [11-14]. The booming sea area exploration brought not only rapid development of marine economy and increase of CSAU collection, but also big problems in the environment and resources. Although the government increased the expenditure in marine environment protection very slightly, the proportion of expenditure against collection was even reduced. This cannot effectively respond to the great environmental pressure generated; such an extensive growth pattern was harmful to the sustainable development of marine economy.

As shown in Figure 10, the CSAU collection during 2002-2012 increased quickly; however, the expenditure increased very slowly. The proportion of CSAU expenditure against collection was unstable, with a trend of climbing first and dropping afterwards and it tended to drop again.

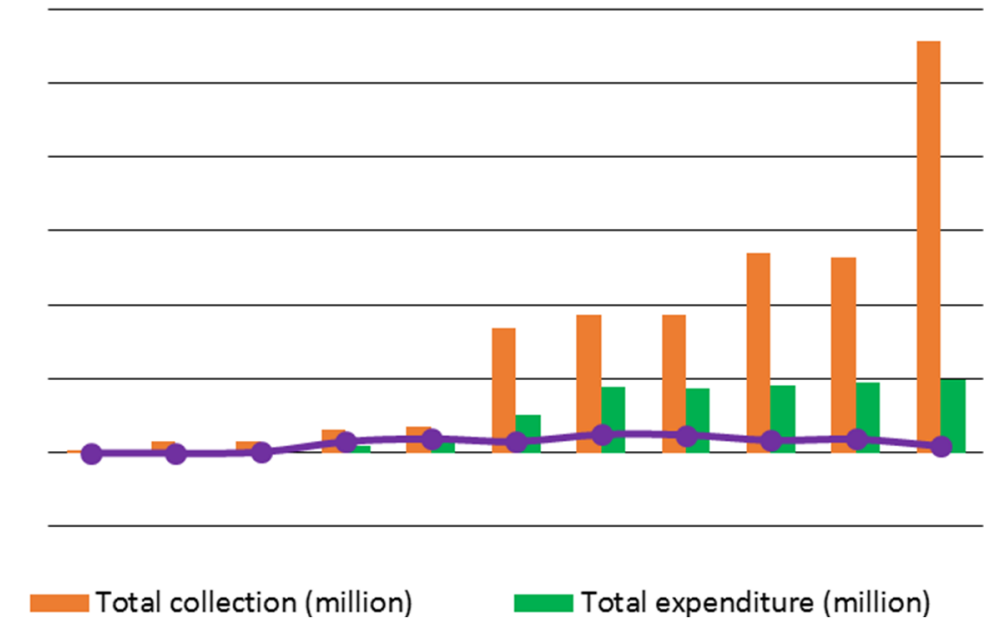

Figure 10. Collection and expenditure of CSAU during 2002-2012 in Guangdong Province.

As shown in Table 4, the CSAU collection kept rising during 2002-2012, with an average annulus growth rate of $98.62 \%$ and the growth rate was more than $100 \%$ in 2003, 2005, 2007 and 2012. Even though the growth rate of the CSAU expenditure was positive for every year but 2009, the amplitude 
was very small during 2009 to 2012, albeit with an average annulus growth rate of $38.78 \%$ which was largely due to the relative high growth rate during 2004 to 2008. The proportion of CSAU expenditure against collection showed a poor performance reflected by a negative growth rate in four out of eight years, with the largest decline in 2012 with a negative growth rate of $-50.31 \%$.

Table 4. Annulus growth of the proportion of CSAU expenditure against collection during 2002-2012 in Guangdong province.

\begin{tabular}{cccc}
\hline Year & CSAU Collection & CSAU Expenditure & $\begin{array}{c}\text { Proportion of CSAU } \\
\text { Expenditure Against Collection }\end{array}$ \\
\hline 2002 & -63.97 & - & - \\
2003 & 467.55 & - & - \\
2004 & 6.57 & 100.00 & - \\
2005 & 106.44 & 94.65 & 805.85 \\
2006 & 11.15 & 25.05 & 20.04 \\
2007 & 392.33 & 75.30 & -17.78 \\
2008 & 11.05 & 43.26 & 58.70 \\
2009 & -0.88 & -3.23 & -2.27 \\
2010 & 46.00 & 4.60 & -28.20 \\
2011 & -2.48 & 4.72 & 7.62 \\
2012 & 111.11 & 4.67 & -50.31 \\
\hline
\end{tabular}

CSAU is an economic instrument, which plays the role of leverage. With appropriate CSAU management, it is possible to achieve the goals of rational exploitation of marine resources and protection of the ecological balance of sea area, as well as the harmonization and maximization of material interests, economic and social benefits. Currently, the sea area use in China includes industrial application, traffic and transportation, entertainment, fishery, land reclamation, waste dumping, education and research and other uses. In Guangdong province, around $85.5 \%$ of the sea area use is for traffic and transportation, industrial application and reclamation. Among them, the traffic and transportation occupies the largest sea area and contributes the most to CSAU. The development of marine economy and increase of local financial revenue are promoted by the process of the channel dredge, shipyards, and nuclear power plants and wharf building. However, these projects destroy the marine environment and resources, an issue which the government did not pay enough attention to. As per the statistics published by the provincial administration department in 2012, 13\% of the sea area is suffering from intermediate or heavy pollution. Faced with these problems, the government can take the two remedial actions. The first action is to properly increase the collection standard of CSAU to restrict excessive marine activities. The second action is to properly distribute the amount of the collected CSAU to marine environment protection and pollution treatment. By doing so, the Tragedy of the Commons can be avoided and to some extent, the sustainable development of the marine economy can be promoted [15].

In summary, the CSAU collection in Guangdong province increased continuously, so did its contribution to the financial revenue; the amount of CSAU expenditure increased slightly and the increasing rate tended to be smaller; the proportion of CSAU expenditure against collection was unstable with negative growth in most years. It was clear that although the CSAU collection became standardized and the sea area use rationalized, the impetus for the CSAU expenditure arrangement was not enough and lagged behind. The proportion of CSAU expenditure against collection tended to reduce and the performance of the CSAU expenditure was not satisfactory. Consequently, the reduced amount of CSAU expenditure would result in the reduction and lagging of expenditure in oceanic infrastructure and marine environment protection and renovation, which would affect the healthy and sustainable utilization of sea area resources and hinder the sustainable development of the marine economy in the future. 


\section{Problems in CSAU Collection and Management in Guangdong Province}

With the fast development of the economy and the progressive improvement of sea area use system, the problems in CSAU collection and management continue to be revealed in the following aspects.

\subsection{Low Efficiency of Sea Area Use, and Lack of Multi-Dimensionality in CSAU Collection}

Although the growth rate of the Authorized Sea Area was faster than GOP, the efficiency was still too low with respect to the acreage and it was still a big investment with small returns. The growth of marine economy has been in an extensive pattern for a long time, leading to the increase in the use of sea area and the consumption of marine resources. The capability of marine exploration and utilization was still low with a trend of extensive expansion, and multi-dimensional comprehensive development and utilization of marine resources has been neglected, resulting in a lot of idle, low usage or even wasted marine resources [7]. The existing Sea Area Use Management Law only has two-dimensional regulation on the sea area paid-use system, i.e., it defines the sea area solely based on the acreage but ignores the multi-dimensional, multi-functional and multi-level comprehensive development features [6,16]. Nowadays, with the emergance of offshore airports, submarine tunnels, artificial islands, sea-spanning bridges and other marine spatial projects, the international trend of utilization of sea area resources is of multi-dimensional and multi-level comprehensive features covering sea-airspace, sea surface, subsurface and submarine. However, the existing Law lacks paid-use regulation for multi-dimensional sea area use, and these legal gaps resulted in a blind zone in CSAU collection, leading to multiple-use in the same sea area without governance. Hence, the sea area use efficiency is low, which is harmful to the rational allocation of sea area resources and affects the sustainable development of marine economy $[7,17]$.

\subsection{Lack of Management Method in the CSAU Collection and Expenditure, and Irrational Distribution Proportion}

With the strengthening of sea area use management, the sea area paid-use system has been implemented deeply all around the country, and the corresponding management methods have been perfected locally to regulate the CSAU management and improve the efficient use of funds. However, the CSAU collection and expenditure in Guangdong province were still implemented based on "Provisional Regulation of CSAU Collection and Expenditure in Guangdong Province" and took the regulation issued by the Ministry of Finance and the State Oceanic Administration as a reference. Therefore, it is necessary for Guangdong to constitute its own management methods suitable for the local marine condition. According to the CSAU collection management in other coastal provinces, the CSAU distribution proportion was clearly defined and well implemented already. For example, Jiangsu province stipulated that the collection of CSAU should be turned over to central, provincial and city/county finance in the proportion of 30:10:60, respectively. However, in Guangdong province, $30 \%$ of the CSAU collection would be turned over to central finance, $70 \%$ to provincial finance and no fixed proportion to city-and-county finance and the distribution was a little random every year $[6,12]$.

\subsection{Lack of Expenditure in the Grass-Roots Units and Inadequate Funds for Marine Affairs}

After reviewing the financial condition at all levels, it was found that $80 \%$ of the CSAU collection turned over to central finance was refunded for expenditure, but less than $30 \%$ of the CSAU collection turned over to the provincial finance was refunded which was too low. Although $63.45 \%$ of the provincial CSAU expenditure was distributed to the city-and-county units, the low refunding amount from provincial finance still restricted the feasible funds in city-and-county units. The basic quota of CSAU collection was very small in some counties' oceanic administrative departments and their expenditure was quite limited, leading to lack of financial support to the grass-roots units in the city-and-county who were the real power to undertake marine exploration, protection and 
management, sea area use coordination, ocean surveillance and other fundamental works. Some oceanic administrative departments at the county level were in heavy debt due to the lack of disposable funds, which indeed damaged their enthusiasm for sea area use management. With the continuous increase in the breadth and depth of off-shore marine resources development and the intensified pollution of the marine environment, the sea area for fishery, the major source of the CSAU collection, became smaller and smaller, resulting in the gradual reduction of the CSAU collection in the counties. Therefore, it was far from enough for the city-and-county units to carry out marine management considering the costs of manpower, material and financial resources. The lack of funding made it very difficult for the grass-roots units to do their jobs. If the situation cannot be improved, the prospective of sustainable development of marine economy will be worrisome.

\subsection{Irrational Structure of CSAU Expenditure}

Guangdong has accumulated rich experience in the development of marine economy and has a high potential for further transformation of economic development and enhancement of the competitiveness. The traditional development pattern based on the development of offshore resources is constrained by the resources and environment. It is difficult to keep a high growth rate primarily due to the irrational marine industry structure, low transformation rate of marine technology to application and weak innovation and competitiveness [18]. According to the application scope of CSAU budget stipulated in "Provisional Regulation of Sea Area Use Charges Expenditure Management" jointly issued by the Ministry of Finance and State Oceanic Administration, the development of marine economy could be effectively promoted by scientific coordination of the CSAU management. The collected CSAU was mainly used in the building of ocean surveillance ships and the renovation and protection of sea area and islands, indicating that the government attached great importance to the infrastructure and environment protection and provided big financial support. Due to lack of institutional regulations on CSAU expenditure management, the local government could not constitute a long-term plan on the CSAU expenditure, resulting in an irrational and arbitrary expenditure structure. Although the marine infrastructure was a fundamental support in maintaining the healthy and sustainable development of marine economy, for those areas with greater potential including marine economy, transformation of marine technology achievements, marine environment monitoring, marine oil spill emergency response system, marine pollution treatment, marine disaster prevention and deep ocean resources exploration, there is still a lack of investment or even no investment in these indispensable areas of the economy and society, which could be harmful to the future development of marine economy. The government should pay enough attention to this aspect, increase the proportion of CSAU expenditure allocated to marine economy, and optimize the CSAU expenditure structure [19].

\section{Countermeasures}

CSAU is the financial support for the sustainable development of marine exploration, protection and management. It would be beneficial to harmonize central and local interests, promote the implementation of works related to marine exploration and management and the healthy development of marine economy through coordinating the local financial department and ocean administration in CSAU management, and strengthening the dynamic management and effective expenditure of CSAU.

It is suggested to strengthen the management of CSAU collection and expenditure from the following aspects in order to promote the sustainable development of marine economy in Guangdong province.

\subsection{Establishment of Multi-Dimensional Property System for the Sea Area Resources}

At present, two-dimensional pricing is widely used in Guangdong province and all over the country, which does not yet meet the requirement of multi-dimensional comprehensive utilization of sea area, and is not helpful for the scientific and rational exploration and utilization of sea area resources to promote sea areas' long-term sustainable development. A three-dimensional property 
system should be established for sea area resources and adopted into the Sea Area Use Management Law. In addition, the regulation of the property of sea area defined by acreage should be revised. In the management of sea area use, both the multi-utilization status of sea area space and the compatibility of various marine projects should be considered. On the basis of non-mutual exclusion, the sea area use property should be defined by sea-airspace, sea surface, subsurface and submarine vertically according to the specific application for different users, and the CSAU collection should be conducted individually according to its sea area use type. By doing this, the sea area use efficiency could be improved significantly and the low qualitative and unitary utilization of sea area resources could be changed. Consequently, the type and structure of the sea area use will be rationalized, the multi pricing of sea area paid-use system be realized, the comprehensive exploration of sea area resources be promoted, the utilization efficiency of sea area resources be increased, the marine spatial layout be optimized, and eventually the intensive and sustainable development of marine economy will be promoted [6].

\subsection{Perfection of the CSAU Management Policy and Bylaw}

The CSAU management in Guangdong is implemented according to the regulation issued by the State Oceanic Administration, as well as the "Provisional Regulation of CSAU Management in Guangdong Province". It has not been revised for nearly 10 years and does not meet the current requirements for the development of marine economy and the management of the sea area use. Firstly, based on the principle of "taking from the sea, giving back to the sea", in combination with the practical CSAU expenditure management in Guangdong province, it must constitute the latest matching bylaws and regulations including the "CSAU Management Methods in Guangdong Province", "By law of CSAU Collection and Management in Guangdong Province" and "List of CSAU Refunding Supporting Projects" must be revised. It could fill in the gaps in CSAU expenditure management policy. Secondly, it must distribute the CSAU on the principle of "special funds for special use, key projects first", strengthen the subsidies and refunds for the supporting projects like environmental-friendly projects that can enjoy CSAU deductions or exemptions, realize effective allocation in the CSAU expenditure, and promote the healthy development of marine economy in Guangdong province. Thus, it is suggested to formulate practical management methods and supporting details of CSAU collection and expenditure, introduce an integrated system of CSAU refunding, expenditure and management, and solve the problems occurring in sea area use management in order to ultimately provide more financial security and support for the construction of Marine Economically Strong Province, and provide legal support for sustainable growth of the marine economy.

\subsection{Rational Distribution of CSAU Expenditure at All Levels}

In the context of construction of marine economically strong province, it is necessary for Guangdong province to increase the distribution proportion of CSAU to the locals to arouse the enthusiasm for sea area management in local coastal governments and push forward the sustainable development of the marine economy. Therefore, a rational proportion of CSAU distribution between the province and city-and-county units should be defined not only based on the implementation of CSAU management methods, but also based on the relevant management measures from other coastal provinces and municipalities. Thus, it is suggested to build a rational mechanism of the distribution of CSAU collection, adjust its distribution proportion, coordinate the benefits distribution from sea area resources by giving priority to the city-and-county units, strengthen the marine management system at all levels, enhance the comprehensive management of sea area and push forward the rapid growth of marine economy. The profit distribution mechanism of Land and Resources Ministry could be used as a reference for the distribution of provincial CSAU expenditure $[20,21]$. That is, for the CSAU collected from the projects approved by the provincial government, $30 \%$ would be turned over to central finance, $20 \%$ to provincial finance, $20 \%$ to the city level and $30 \%$ to the county level. Another option is to coordinate the profits at all levels, define a fixed distribution mechanism favoring the 
city-and-county, and offer further distribution in the form of bonus as per the actual progress in local marine economy development and CSAU collection and management performance. Ultimately, the CSAU distribution to the locals could be increased effectively and CSAU could function as the financial security for marine exploration and management so as to increase the supporting funds to grass-roots units and enhance their enthusiasm.

\subsection{Optimization of the CSAU Expenditure Structure}

Guangdong province is now focusing on various programs especially "Accelerating Transformation and Upgrading, Building A Happy Guangdong", and it needs a strong support from the financial policy. As a financial leverage, CSAU would be an important guarantee for Guangdong to build an economically strong marine province and realize the sustainable development of marine economy. However, the refunds from provincial CSAU are still inadequate and the guidance of financial investment is not enough, which can neither increase the provincial CSAU expenditure efficiency nor effectively enhance the sea area management capacity, nor formulate a regular mechanism of increasing investment in marine commonweal, including marine environmental protection, disaster prevention and mitigation. With the development of marine economy in the coastal cities, besides ensuring stable CSAU refunding, it is suggested to optimize the expenditure structure of CSAU refunding, emphasize the promoting effect of CSAU expenditure on the growth of marine economy. We reccommend: increasing the spending on supervision of marine economic operation, arranging proper funding for the development of strategic marine industries, such as marine engineering equipment manufacturing industry, improving science and technology transformation rate, promoting the building of marine information management system, supporting construction of marine infrastructure especially at the city and county level, improving the service in marine commonweal, such as environmental protection, disaster prevention and mitigation, and contributing to the building of a marine economically strong province in Guangdong.

\subsection{Enhancement of the Supervision and Management System in CSAU Expenditure}

Currently, in Guangdong province there is no clearly defined regulation with regard to the proportion of CSAU collection used for the operating expenses of collection and management. The said proportion should be defined based on the actual situation of Guangdong province, together with the proportions of other coastal provinces as references. For example, the above-mentioned expense is not considered for financial department at city-and-county level and no more than $3 \%$ of CSAU collection could be used as the expenses of collection and management but not as other risk cost in the financial department of the province. The provincial finance should enhance the CSAU comprehensive management and bring CSAU collection and expenditure into special management. Meanwhile, based on the coordinating mechanism of CSAU comprehensive management, the CSAU reconciliation system should be set up, a financial support strategy suitable for the Guangdong's practical condition should be formulated, and the special funds for the development of marine economy in the ocean related departments should be integrated and coordinated. With the profits as the premises of supporting the development, a scientific, rational, workable performance evaluation system for the financial support to marine economic development should be established [22]. Thus, one not only has the performance targets before starting the task, but also can track and evaluate the performance targets during and after the task [12]. This will be very helpful for the realization of the organic integration of financial management and budget management, as well as the linkage of CSAU revenue to the actual profits. More support should be provided to those projects with rational targets and excellent performance; on the contrary, less or no support should be provided to those projects with poor targets and performance in order to make sure that the CSAU refunding plays a better role in the construction of marine economy $[12,19,22]$.

The supervision of CSAU should be further strengthened on the basis of its effective collection and management. The CSAU collected at all levels should be included in budget management. 
Based on the principle of "special funds for special use", the collection should be mainly used in the development of marine economy, marine management, marine informatization, sea area renovation, etc. Project management of sea area use investment should be regularized and strengthened and project performance appraisal systems should be established to improve the efficiency of CSAU expenditure. The supervision and inspection of the management of CSAU collection and expenditure should be strengthened; those who violate discipline should be punished severely; the expenditure of CSAU refunding from central and the locals should be inspected periodically and the audit and inspection of CSAU refunding supported projects should be strengthened [19].

Regarding CSAU management, in addition to administrative and economic means, oceanic administrative department must strengthen public awareness of the protection of the oceans from a strategic perspective with the scientific use of educational propaganda to achieve sustainable development of the sea area.

\section{Conclusions}

The formulation of China's sea area utilization governance policy is in the evolution process, and the CSAU's collection and expenditure management are also constantly improving, which is not only helpful for the improvement of sea area paid-use mechanism, but also of meaningful importance in the increasing efficiency of sea area's utilization and the sustainable development of marine economy. It was shown in this study that, since the implementation of sea area paid-use mechanism, especially in the decade since the issuance of Sea Area Use Management Law, the sea area property system developed continuously, which effectively protected the sea area resources from plundering. The collection of CSAU greatly increases the efficiency of sea area utilization, ensures the sustainable exploration and utilization of sea area resources, promotes the healthy development of marine economy and promotes the growth of local economy. Meanwhile, the expenditure of CSAU also increases every year, and is mainly used in the construction of marine infrastructure and the renovation of sea area and islands. However, there are still some irrational phenomena in the collection and expenditure of CSAU in Guangdong province. The collection from traffic and transportation and industrial sea use contributes a lot to the CSAU and increases the financial revenue, but the subsequent environment and pollution problems have not attracted enough attention. Moreover, the expenditure of CSAU is still inadequate in supporting the sustainable development of marine economy, which is not helpful for the CSAU to provide better leverage. Since the CSAU management system in Guangdong and even the entire country is still not perfect, the local government should constitute viable CSAU management policy and perfect the economic measures of CSAU management, for example, establishing a multi-dimensional property system for the sea area resources, perfecting the management policy in CSAU expenditure, optimizing CSAU expenditure structure, enhancing the supervision and management of CSAU expenditure, in order to accelerate the transformation of sea area resources to intensive utilization, bringing the exploration potentiality of sea area resources into full play and promoting the sustainable development of marine economy.

Acknowledgments: This work was supported by the Ocean Public Welfare Project, State Oceanic Administration People's Republic of China (Grant No. 201405029) and the President Fund, South China Sea Branch of State Oceanic Administration. The authors would like to thank the editors and the anonymous reviewers for their valuable comments and suggestions.

Author Contributions: Lijing Yang and Linglong Cao designed this research. Lijing Yang and Ping Wang collected and interpreted the data and wrote the paper with significant contributions from other authors. Yongjian Liu provided support in performing the data analysis. Lei Chen made constructive comments. All authors have read and approved the final manuscript.

Conflicts of Interest: The authors declare no conflict of interest. 


\section{References}

1. Pioch, S.; Saussola, P.; Kilfoyleb, K.; Spieler, R. Ecological design of marine construction for socio-economic benefits: Ecosystem integration of a pipeline in coral reef area. Procedia Environ. Sci. 2011, 9, $148-152$. [CrossRef]

2. Basurko, O.C.; Mesbahi, E. Methodology for the sustainability assessment of marine technologies. J. Clean. Prod. 2014, 68, 155-164. [CrossRef]

3. Visbeck, M.; Kronfeld-Goharani, U.; Neumann, B.; Rickels, W.; Schmidt, J.; van Doorn, E.; Matz-Lück, N.; Ott, K.; Quaas, M.F. Securing blue wealth: The need for a special sustainable development goal for the ocean and coasts. Mar. Pol. 2014, 48, 184-191. [CrossRef]

4. Mingli, Z.; Dewei, Y.; Ping, W.; Ping, S. A market-based approach to marine sand resource management in the Pearl River estuary, China. Ocean Coast Manag. 2015, 105, 56-64.

5. Cao, L.; Tian, H.; Yang, J.; Shi, P.; Lou, Q.; Waxi, L.; Ni, Z.X.; Peng, X.J. Multivariate Analyses and Evaluation of Heavy Metals by Chemometric BCR Sequential Extraction Method in Surface Sediments from Lingdingyang Bay, South China. Sustainability 2015, 7, 4938-4951. [CrossRef]

6. Department Of Finance of Guangdong Province. Regulate the management of sea area use charges' collection and expenditure to push forward marine economy's rapid development. China Finance. 2011, 17, 60-61.

7. Zhang, S.; Wang, M. Implement and improvement of sea area paid-use system in China. Economic Aspect 2015, 1, 33-37.

8. State Oceanic Administration People's Republic of China. Sea Area Management Bulletin (2002-2012). Available online: http://www.soa.gov.cn/zwgk/hygb/ (accessed on 10 May 2014). (In Chinese).

9. State Oceanic Administration People's Republic of China. China Marine Statistical Yearbook; 2003-2013; China Ocean Press: Beijing, China, 2003-2013. (In Chinese).

10. Statistics Bureau of Guangdong Province. Guangdong Statistical Yearbook; 2013; China Statistics Press: Beijing, China, 2013.

11. Zhang, S. The Influence Study on Sea Area Use to Marine Economy Growth in our Country. Master's Thesis, Ocean University of China, Qingdao, China, 2014.

12. Mao, X.F. The problems in sea area use charges collection and management and the countermeasure. Financial superv. 2007, 3, 32-33.

13. Xu, X.M.; Mei, F.; Shi, J. Sea Area Paid-Use System in China; China Environment Science Press: Beijing, China, 2009.

14. Pan, X.C. Introduction to Sea Area Governance; Ocean Press: Beijing, China, 2014.

15. Gao, Z.G. China's Ocean Development Report 2015; Ocean Press: Beijing, China, 2015.

16. Reshaping the Governance for Sustainable Development. China Sustainale Development Report 2015; Science Press: Beijing, China, 2015.

17. Zhang, S.; Wang, M. Sea Area Utlization Charge Management's Effect in China and its Analysis. Price theory Pract. 2015, 1, 62-64.

18. Xiang, X.M. An Evaluation of the Competitivity of Guangdong Maritime Economy. China Open. J. 2013, 1, 14-19.

19. Yang, L.J. Financial Routes and Countermeasures on the Construction of Marine Economically Strong Province-Taking Guangdong Province as Example. Local financial resear. 2013, 11, 63-68.

20. The Central People's Government of the People's Republic of China. Regulation on the Management of Collection and Expenditure from the Transfer of State-owned Lands. Availalbe online: http:/ /www.gov.cn/ gongbao/content/2007/content_503389.htm (accessed on 11 June 2014).

21. Ministry of Finance. National Land Use Right Paid-Use Charges Management Provisional Regulation, China, 1989; Coucil of State City: Beijing, China, 1989. (In Chinese).

22. Yu, G.A. Research on the Financial Hot Issues; Economic Science Press: Beijing, China, 2011.

(C) 2016 by the authors; licensee MDPI, Basel, Switzerland. This article is an open access article distributed under the terms and conditions of the Creative Commons by Attribution (CC-BY) license (http:/ / creativecommons.org/licenses/by/4.0/). 